\title{
Castration Refractory Prostate Cancer: Cinderella Finally Comes to the Ball
}

\author{
Simon Chowdhury ${ }^{\mathrm{a}}$ Peter Harper ${ }^{\mathrm{a}}$ Thomas Powles ${ }^{\mathrm{b}}$ \\ aDepartment of Medical Oncology, Guy's and St Thomas' Hospital, \\ ${ }^{b}$ Department of Medical Oncology, St Bartholomew's Hospital, London, UK
}

Prostate cancer is the second most common cause of cancer related mortality in men in the developed world [1]. Androgen deprivation therapy (ADT) is highly effective in the treatment of advanced prostate cancer and is the standard first line treatment. Despite this virtually all patients become resistant to ADT developing castration refractory prostate cancer (CRPC) and current systemic treatment options for this lethal disease state are limited. Docetaxel has played an important role in the treatment of CRPC with a median improvement in survival of 3 months and improved quality of life [2]. However, until recently, there were no treatments showing a survival benefit post-docetaxel and this is an important area of unmet clinical need.

Historically castration resistant tumours were thought to develop without reliance on the androgen receptor and were characterised as 'hormone refractory' or 'androgen independent'. Recent research has however shown that signalling via the androgen receptor (AR) continues despite castrate levels of androgens in CRPC [3-4]. The exact mechanisms remain unknown but supporting evidence for the AR's importance comes from the much greater than expected tissue concentrations of androgens in the tumour microenvironment in CRPC. In addition both AR overexpression and amplification are often seen in CRPC and AR-mediated signalling may become hypersensitive to androgens. AR signalling may also be enhanced through the activation of various growth factors and increased expression of co-activators and decreased expression of co-repressors. Thus AR signalling remains a critical pathway stimulating tumour growth despite castrate levels of androgens.

Androgen deprivation therapy stops gonadal production of testosterone but despite ADT circulating levels of testosterone up to $10 \%$ of precastrate levels may persist as a result of production of androgens from the adrenal glands or the tumour itself [5]. The realisation that the androgen receptor retains importance in CRPC has led to renewed interest in androgen signalling targeted treatment. The first such drug to show a definite clinical benefit is abiraterone acetate. Abiraterone acetate, and its active metabolite abiraterone, are potent, selective and irreversible inhibitors of CYP17 $\alpha$ hydroxylase and $\mathrm{C}_{17,20}$-lyase that catalyse two essential steps in androgen biosynthesis [6]. Abiraterone markedly decreases levels of androgens in CRPC and initial phase I and II clinical trials showed promising activity and confirmed that a subgroup of CRPC patients continue to have androgen-driven disease [6-7].

A phase III study of abiraterone acetate in metastatic CRPC post-docetaxel has just reported its results at this year's European Society of Medical Oncology (ESMO) annual meeting [8]. This study randomised 1,195 patients previously treated with 1 or 2 chemotherapy regimens, at least one of which contained docetaxel, to abiraterone acetate plus prednisolone versus prednisolone alone in a 2:1 manner. Treatment with abiraterone acetate resulted in a $35 \%$ reduction in the risk of death $(\mathrm{HR}=0.65: 95 \% \mathrm{CI}: 0.54,0.77 ; \mathrm{p}<0.0001)$ and a $36 \%$ increase in improvement in median overall survival (14.8 vs. 10.9 months). Patients in the abiraterone arm experienced more mineralocorticoid-related adverse events, most notably fluid retention, hypokalaemia and hypertension, but toxicities were manageable and the treatment was generally well tolerated.

The results from this study are truly practise changing and will benefit patients who for too long have not had active treatment options. With the positive phase III studies of sipuleucel-T [9] and cabazitaxel [10] this has been a year of great progress for the treatment of CRPC. Abiraterone is now being evaluated in a large phase III study in asymptomatic or mildly symptomatic patients with metastatic CRPC who have not received chemotherapy. This trial has completed accrual and its results are eagerly awaited. Abiraterone has shown that 'androgen-independent' or 'hormone refractory' disease is neither of these things and that androgen receptor signalling remains a relevant therapeutic target and a key area for current and future research.

\section{KARGER}

Fax +497614520714

Information@Karger.de

www.karger.com
(C) 2010 S. Karger GmbH, Freiburg

Accessible online at:

www.karger.com/onk
Dr. Simon Chowdhury

Department of Medical Oncology

Guy's and St Thomas' Hospital

London SE1 9RT, UK

Tel. +44 207 188-3269, fax -4271

simon.chowdhury@gstt.nhs.uk 


\section{Conflict of Interest}

SC: Consultant or advisory role: Dendreon, Sanofi-Aventis,

Janssen-Cilag. PH + TP: Consultant: Sanofi-Aventis.

\section{References}

1 National Cancer Institute: Surveillance, Epidemiology and End Results. www.seer.cancer.gov.

2 Tannock IF, de Wit R, Berry WR et al.: Docetaxe plus prednisone or mitozantrone plus prednisone for advanced prostate cancer. $\mathrm{N}$ Engl $\mathrm{J}$ Med 2004;351:1502-12.

$>3$ Pienta KJ, Bradley D: Mechanisms underlying the development of androgen-independent prostate cancer. Clin Cancer Res 2006;12:1665-1671.

4 Holzbeierlein J, Lal P, LaTulippe E et al.: Gene expression analysis of human prostate carcinoma during hormonal therapy identifies androgen responsive genes and mechanisms of therapy resistance. Am J Pathol 2004:164:217-227.
5 Stanbrough M, Bubley GJ, Ross K et al.: Increased expression of genes converting adrenal androgens to testosterone in androgen-independent prostate cancer. Cancer Res 2006;66:2815-2825.

6 Attard G, Reid AH, Yap TA et al.: Phase I clinical trial of a selective inhibitor of CYP17, abiraterone acetate, confirms that castration-resistant prostate cancer commonly remains hormone driven. J Clin Oncol 2008;26:4563-4571.

7 Attard G, Reid AH, A'Hern R et al.: Selective inhibition of CYP17 with abiraterone acetate is highly active in the treatment of castration-resistant prostate cancer. J Clin Oncol 2009;27:37423748.
8 De Bono JS: LBA5- Abiraterone acetate (AA) plus low dose prednisone $(\mathrm{P})$ improves overal survival (OS) in patients (pts) with metastatic castration-resistant prostate cancer who have progressed after docetaxel-based chemotherapy: results of COU-AA-301, a randomised double blind placebo-controlled trial. ESMO 2010; Abstr. LBA5

9 Kantoff PW, Higano CS, Shore ND et al.: Sipuleucel-T for castration resistant prostate cancer. N Engl J Med 2010;363: 411-422.

10 De Bono JS, Oudard S, Ozguroglu M et al.: Prednisolone plus cabazitaxel or mitoxantrone for metastatic castration-resistant prostate cancer progressing after docetaxel treatment: an open label trial. Lancet 2010;376:1147-1154. 